American Journal of Pharmaceutical Education 2019; 83 (3) Article 6554.

\title{
RESEARCH
}

\section{A Comprehensive Reflective Journal-Writing Framework for Pharmacy Students to Increase Self-Awareness and Develop Actionable Goals}

Jeremy A. Hughes, PharmD, ${ }^{\mathrm{a}}$ Anita J. Cleven, PharmD, ${ }^{\mathrm{b}}$ Jackson Ross, MA, ${ }^{\mathrm{b}}$ David G. Fuentes, PharmD, ${ }^{\mathrm{a}, \mathrm{c}}$ Fawzy Elbarbry, PhD, MSPharm, BSPharm, ${ }^{\mathrm{b}}$ Marina Suzuki, PharmD, PhD, ${ }^{\mathrm{b}}$ Mark Della Paolera, PharmD, ${ }^{\mathrm{d}}$ Nicola S. Carter, PhD, ${ }^{\mathrm{b}}$ Brendan Stamper, PhD, ${ }^{\mathrm{b}}$ Pauline Low, PharmD, ${ }^{\mathrm{b}}$ Ashim Malhotra, PhD, BPharm, ${ }^{\mathrm{e}}$ Sarah Jane E. Faro, PharmD ${ }^{\mathrm{b}}$

${ }^{\text {a }}$ California Health Sciences University, College of Pharmacy, Clovis, California

${ }^{b}$ Pacific University Oregon, College of Health Professions, School of Pharmacy, Hillsboro, Oregon

${ }^{c}$ Editorial Board Member, American Journal of Pharmaceutical Education, Arlington, Virginia

${ }^{\mathrm{d}}$ AstraZeneca, Portland, Oregon

${ }^{\mathrm{e}}$ California Northstate University, College of Pharmacy, Elk Grove, California

Submitted May 31, 2017; accepted September 3, 2017; published April 2019.

Objective. To develop and evaluate the effectiveness of a structured model for reflective journal writing (RJW) and a grading rubric as part of a student portfolio designed to help Doctor of Pharmacy (PharmD) students create actionable goals.

Methods. A structured, eight-domain format was developed to engage students in prioritization, identification, exploration, recollection, evaluation, and challenging/solidifying their own knowledge, while assembling an action plan for development (abbreviated using the acronym PIE-RECAP). After completing RJW using this model, students self-identified domains established by the Center for the Advancement of Pharmacy Education (CAPE) that corresponded to their entries. A grading rubric was designed and normalized to require minimal training for use. RJW and other elements of student portfolios were implemented simultaneously across three cohorts $(\mathrm{N}=296)$. Twenty-one faculty and staff graders each evaluated 10 to 15 student journal entries.

Results. Of 771 journal entries, 648 (84\%) met expectations, while 123 (16\%) needed to be rewritten. Students identified experiences that were meaningful to them and shared in their RJW entry the knowledge and/or information that they did not know prior to the experience. Common themes identified in the students' RJWs included: curricular experiences $(12.7 \%)$, cocurricular experiences (18.4\%), and experiential training $(68.6 \%)$.

Conclusion. The PIE-RECAP method can be used to guide students in RJW and identify CAPE domains in their personal and professional experiences in pharmacy school. The associated grading rubric can be used to evaluate students' RJW entries and assess their growth in curricular, cocurricular and affective domains relative to their progression.

Keywords: reflection, student experiences, assessment, self-awareness, co-curriculum

\section{INTRODUCTION}

Components of self-reflection have been used in continuous professional development models for professionals in pharmacy, other health care fields, and many other disciplines and specialties, including law, business, and education. ${ }^{1-21}$

Corresponding Author: Jeremy A. Hughes, California Health Sciences University, College of Pharmacy, $120 \mathrm{~N}$. Clovis Ave., Clovis, CA 93612. Tel: 559-546-6049. Fax: 559473-1487. E-mail: j.hughes@chsu.edu

Note: At the time of manuscript submission, Drs. Hughes, Fuentes, Della Paolera, and Malhotra were affiliated with Pacific University Oregon.
These models help promote reflection on past experiences, stimulate learning, and ultimately provide new insights to enhance their practice. ${ }^{1-5,12-16}$ Students within these professions, disciplines, and specialty areas have been exposed to a variety of self-reflection methods and tools that allow them to meet an array of student learning outcomes including refining their written communication skills, learning to think and use metacognition, linking learned information to practical applications, and many others. ${ }^{2,4-8,11,13,21}$ The significance of selfreflection as a cognition tool is well-recognized and has been used with students enrolled in K-12, undergraduate, graduate, and postgraduate education. The Accreditation 


\section{American Journal of Pharmaceutical Education 2019; 83 (3) Article 6554.}

Council for Pharmacy Education's (ACPE's) current accreditation standards or "Standards 2016," direct pharmacy programs to provide students with opportunities to develop competencies in the areas of effectively educating others, thinking in innovative ways to improve their approach to practice, and becoming more self-aware, and to constantly develop their skill sets, as well as to meet more complex development goals in key areas according to key learning taxonomies. ${ }^{22-24}$

Publications on reflective journal writing (RJW) exist within the pharmacy literature as well as in other health professions and general education literature. ${ }^{1-3,6-10,17-21}$ Formats for RJW have included in-class extemporaneous assignments, course-long assignments, real-time journal entries, and other strategies based on discipline-specific outcomes. $^{2,6-9,18-20}$ Low technology (paper-pen/pencil) and higher technology (course management systems) have been used to enable faculty members to use RJW as an assignment in traditional, in-person education, and online, distance-based education. ${ }^{1-9}$ Researchers have created a variety of rubrics that reflect the values of faculty members using RJW as well as the values of their respective institutions. These rubrics have yielded outcomes related to the utility, significance, and curricular and programmatic impact of RJW assignments. Students have had diverse reactions to RJW assignments, with some commenting on how beneficial these exercises were, and others describing how they did not understand the value of reflection. $3,4,6,16,25,26$

At the Pacific University Oregon School of Pharmacy (PUSOP), we developed and implemented an innovative RJW model to help pharmacy students practice written communication; familiarize themselves with the program's values and ability-based outcomes; develop specific, measurable, actionable, realistic, and timelinked (SMART) goals; and engage in meaningful interactions with our program's faculty members, staff, and administrators to promote lasting connections.

In the PUSOP program, we believe that self-reflection is an ideal way for students to learn from their past experiences and behaviors, as well as to critically evaluate the events they find most meaningful as they progress through the program. Therefore, we integrated RJW as a key component of our co-curriculum within the students' required professional portfolio system.

Pacific University Oregon School of Pharmacy (PUSOP) is a three-year, accelerated doctor of pharmacy (PharmD) program, valuing integration of classroom foundational, social/administrative, and clinical sciences with experiential training to develop practice-ready clinicians and leaders. Since the program's inception in 2006, the administrators, faculty, and staff have embraced a philosophy to inculcate self-directed learning in a learner- centered environment. The university has historically used RJW and portfolios to document student development as we believe these provide valuable insight into students' perceptions of their learning, while documenting their continuous professional growth. ${ }^{27-31}$ However, the quality of students' RJW entries was inconsistent, and early efforts at creating portfolios often produced cumbersome and impractical bound hard copies.

Additionally, our previous portfolio process was hampered by faculty turnover and/or limited faculty availability and participation. Herein, we describe a RJW model and a reflection assessment rubric (RAR), how they fit into our pharmacy student portfolio system (PSPS), and how these have incorporated valuable lessons from prior experiences; discuss the level of engagement for faculty, staff, and external affiliated stakeholders; summarize the use of evidence-based educational theories, technology, and rubric development to establish the value and utility of PSPS; outline the components of our RJW model (PIE-RECAP) and RAR to better define the length, depth, and quality of reflections; and, highlight how our RJW model and RAR link to our mission, programmatic ability-based outcomes (ABOs), the Center for the Advancement of Pharmacy Education (CAPE) 2013 Educational Outcomes, ACPE Standards 2016, and National Association of Boards of Pharmacy (NABP) North American Pharmacist Licensure Examination (NAPLEX) competencies. We describe our RJW model, which allows students to reflect on their selfidentified meaningful experiences within our program, select and prioritize one of those experiences for contemplation, revisit that experience through various diverse lenses, critically evaluate the experience, identify how this experience either has built upon or contradicted their prior knowledge, and develop an action plan to approach similar situations with enhanced outcomes in the future.

\section{METHODS}

As of the start of the 2014-2015 academic year, our program did not have a consistent reflective journal writing assignment or model. Based on joint meetings between our program's curriculum and assessment committees, as well as on the evolving Standards 2016 and CAPE 2013 educational outcomes, faculty members agreed that our program would benefit from the development of an RJW model housed within a professional portfolio system. The Office of Experiential Education and the Office of Academics and Assessments worked collaboratively to develop the portfolio system and the RJW model, which we refined and integrated with the help of actively engaged faculty and staff members throughout the 2014-2015 academic year. The process was introduced to students at the start of the 2015-2016 academic year. 


\section{American Journal of Pharmaceutical Education 2019; 83 (3) Article 6554.}

Specifically related to the RJW process, relevant articles from the literature on educational theory, educational psychology, instructional design, and teaching philosophies were consulted in order to develop a framework grounded in constructivist teaching and learning theory, as well as a framework that engaged students in cognitive, social, and transformative learning. ${ }^{13,21,23,24}$ Faculty and staff assistance and internal grant funding were instrumental in allowing us to vet the RJW model and refine the assessment rubric for the reflections. Faculty and staff members were engaged in a multi-step process to clarify instructions and expectations for students. Faculty graders completed norming sessions on the grading and rubric structure. Student committee representatives and students on academic advanced pharmacy practice experiences (APPEs) also were included in the refinement process. The PIE-RECAP and RAR were strategically aligned to the program's revised strategic plan and key niche areas. The PIE-RECAP allowed the program to gain a deeper knowledge of students as individuals through their RJW and allowed students to reflect on experiences throughout the curriculum and co-curriculum, including unique experiences in classroom and experiential settings.

Final refinements of the RJW model and rubric culminated in an eight-step reflection process that required 13 entries per student/curricular career; used a "meet/does not meet" approach to grading the reflections, with faculty feedback being an important component of the grading; was not tethered to any one course or experience; allowed students full autonomy over what they chose to reflect on and write about; and served as a strategy to promote deeper connections between faculty and students. The eight steps of the PIE-RECAP reflective journal-writing model, with each step corresponding to a letter within the acronym, are described in Figure 1.

In the initial section of the PIE-RECAP, students were asked to prioritize $(\mathrm{P})$ by listing three significant learning experiences two to three times per academic year. This process encouraged the students to reflect on the entire program, including curricular, cocurricular, and personal learning experiences that had occurred since their last RJW entry. This component blended social, behavioral, and cognitive learning experiences with selfdirected learning theories. ${ }^{13,21,23,24}$ In the second section, students were asked to identify (I) the one, most important learning experience they had had and use that experience as they worked through the entire RJW framework. This section compelled students to choose the experience to which they had the greatest connection. The third section asked students to explore the situation objectively. They were asked to remember the occurrences linked to this

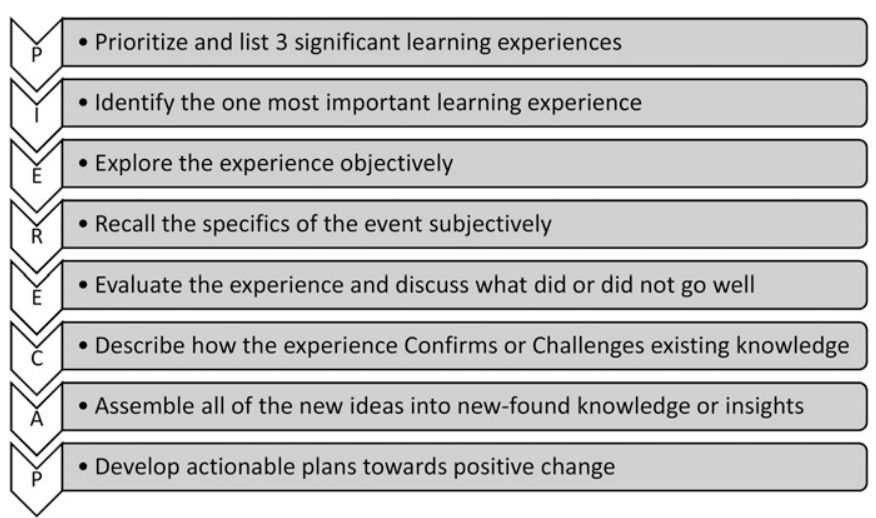

Figure 1. Schematic Illustration of the PIE-RECAP Model

specific RJW entry and identify only the facts, such as what was said or what happened, as they remembered them.

In the fourth section, students were asked to recall specifics about the event and use their senses to describe the event. Drawing on memories about the sights, smells, tastes, touches, and/or sounds associated with the experience, they had to describe the experience through a different "lens." Next, students evaluated the experience and discussed what did or did not go well. This section, in conjunction with the previous ones, allowed students to reflect on their own thinking (metacognition), and recognize the different ways one experience can be seen through objective, subjective, and evaluative lenses. In this section, students identified how their experience allowed them to either confirm or challenge their existing knowledge, thoughts, and ideas. Through this section, students could correct their prior assumptions and/or gain confidence through the confirmation and solidification of prior knowledge.

In section $\mathrm{A}$, students assembled their new-found ideas and knowledge, commenting on how the entire experience modified their thinking, confidence, skills, or attitudes. This stage was similar to the synthesis phase of learning achieved on Bloom's cognitive learning taxonomy and leads to action-oriented transformative learning. ${ }^{23,24}$ Transformative learning took place during this section, where students were asked explicitly to blend new insights together in preparation for the final stage. Finally, students were asked to develop actionable plans for positive change. The plans they developed had to follow the specific-measurable-attainable-realistic-timely (SMART) model. Through these sections, we not only challenged students to recall an experience, we also wanted them to develop cognitively and follow a framework that enabled them to see and access their previous entries and work so they could better visualize their own personal and professional transformation as they 


\section{American Journal of Pharmaceutical Education 2019; 83 (3) Article 6554.}

advanced through the pharmacy program. This goal of the RJW project actualized the concept of metacognition by providing students with a tool to temporally chart and visualize their own professional growth. In our program, students were not required to follow-up on their action or to continue to build upon it in future entries, although they could do so if they chose. Faculty advisors used the portfolio system and RJW entries to have conversations with students about the goals they developed. This was not a graded element of the program but rather a cocurricular experience. With the faculty advisors' help, students were able to discuss their goals and engage in deeper discussion, realizing the metacognitive and positive change elements as they engaged in coaching and mentorship with their faculty advisors.

Once the process was more refined and well developed, faculty and staff members were recruited to grade the students' reflections. The rubric complementing the PIE-RECAP model was finalized, and training sessions were held with the faculty and staff members on how to grade the students' reflections and effectively use the rubric (Appendix 1).

Connecting the elements included in the PIE-RECAP to the CAPE 2013 and ACPE 2016 guidelines was essential to the success of our program. The PIE-RECAP allowed students to reflect on any of the areas in the first two domains, as well as cognitively develop and condition their mindset to make connections in the third and fourth domains. ${ }^{22}$ In order for students to develop the ability to make connections between activities and our $\mathrm{ABOs}$, we provided them with training during orientation on how to connect activities to these domains. We emphasized that there was no one correct answer. We explained that when considering a specific experience, such as a health fair screening for high blood pressure, different students might make different $\mathrm{ABO}$ connections. For example, in such a health screening, some students might focus intently on a medication the patient is using, selecting Domain 1, and emphasizing knowledge and pharmacy practice skills. Another student might choose a similar experience but focus on the communication barriers they encountered in interacting with an individual who spoke limited English, thus selecting Domain 3 and emphasizing communication.

As we continued to develop the technological infrastructure to collect and house the RJW entries, we also developed a mechanism by which students would selfidentify the most relevant educational outcomes and/or standards. In this way, we ensured that our students were receiving repeated reinforcement and exposure to the ultimate outcomes of their education. Additionally, because our ABOs were based on CAPE 2013 and ACPE 2016, as well as linked to the NAPLEX competencies, we have identified specific programmatic ABO statements aligning with PIE-RECAP, as well as with the RAR. The PIERECAP and RAR were developed with emphasis on whether or not students met the standards, as well as on the quality of their written communication. Students were asked to emphasize clarity and depth in their RJW entries. Students earning a "does not meet" in any section had to make alterations and resubmit the entry based on grader feedback as well as their own ideas. From the RAR, it was possible to determine whether students had success or difficulty with any of the eight sections. The RAR instrument was continuously assessed during the various norming sessions to gather data on agreement across graders. From these data, we provided valuable feedback to students, developed helpful strategies to train future graders and students on RJW, and improved the RAR to make expectations clearer to all parties involved.

Finally, a survey was conducted in the spring semester of the 2016-2017 academic year to evaluate student and faculty perceptions regarding the RJW process, related workload and perceived value. The RJW entries were analyzed by assigning each entry to one of the following broad themes: curriculum, co-curriculum, student services, and experiential learning. The four domain areas aligned with our curricular values, as well as with the student experience. Within each of these areas, we identified subcategories to help further classify the entries. These subcategories included: specific course and study areas within the curriculum, interprofessional education, community/health service, professionalization, leadership development, self-awareness, perseverance, practice skills, research, career development, patient interactions, teaching, mentorship, and collaborative learning. An assistant dean in student affairs and an assistant dean in academics and assessment reviewed the qualitative data. Each entry was coded independently by the two administrators. Any discrepancies were discussed until there was agreement. There were no instances where agreement was not reached. Additionally, each entry was reviewed to see how students themselves connected the experience to one or more of the program's ABOs.

\section{RESULTS}

Two hundred ninety-six pharmacy students across all cohorts participated in the PIE-RECAP RJW model within our three-year accelerated program. Most students (98\%) met the initial deadlines for their submissions, and automated reminder emails resulted in all students submitting every assignment. During the 2015-2016 academic year, 21 faculty and staff members within the program participated as graders, each grading about 


\section{American Journal of Pharmaceutical Education 2019; 83 (3) Article 6554.}

10-15 entries. Students' entries were assigned to their faculty advisor whenever possible. Participation in the program was optional for faculty members, and student entries could not always be matched to their respective faculty advisors. Over the 2015-2016 academic year, 85 P3 students participated in the RJW process and completed three entries during the year for a total of 255 entries. Also, 112 P2 students completed two entries each that year for a total of 224 entries. Finally, we had 98 first-year (P1) students who completed three entries that year, totaling 294 entries. Of the 773 students' entries, two were submitted late and thus not included in the original analysis. Students not submitting RJW entries on time were referred to the student progression committee for professionalism issues.

Some of the common themes identified in the students' 771 entries during the 2015-2016 academic year included curricular experiences $(12.7 \%)$, cocurricular experiences (18.4\%), and experiences that happened during their IPPEs and APPEs (68.6\%). Other lesser-mentioned areas were categorized as student services. When looking at the differences in the themes identified in each cohort's entries, first-year students starting the program focused on cocurricular experiences $(41 \%)$, curricular experiences (29\%), and experiences during their IPPE training (31\%). Second-year students focused on cocurricular experiences $(16 \%)$, curricular experiences $(9 \%)$, and experiences during their IPPE training (75\%). Third-year students focused on cocurricular experiences $(2 \%)$, curricular experiences $(4 \%)$, and experiences during their APPE training (94\%), with a small number focusing on their experiences with student advising and student services (Figure 2).

Examining the reflection themes more in depth, the most commonly seen theme that students across all three cohorts reflected on was in the area of practice skills $(38 \%)$. Other areas included patient interactions $(12.6 \%)$ and community and health care service (7.3\%). Less commonly seen theme areas reported by students included teaching patients, providers, peers, or family members $(5.6 \%)$, self-awareness $(5.4 \%)$, professionalization (5.3\%), career development (4.1\%), and interprofessional education (4.1\%).

Deeper comparison of these thematic areas across cohorts revealed that $\mathrm{P} 2$ students reflected on practice skills-related experiences in $55 \%$ of their entries, while second-year (P2) students did so in $45.2 \%$ of their entries, and $\mathrm{P} 1$ students reflected as such in only $6.6 \%$ of their entries. In the area of patient interactions, P1 students reflected on the value of interacting with patients in $25 \%$ of their entries, while third-year (P3) students did so in $11 \%$, and P2 students did so in $4.8 \%$. In relation to

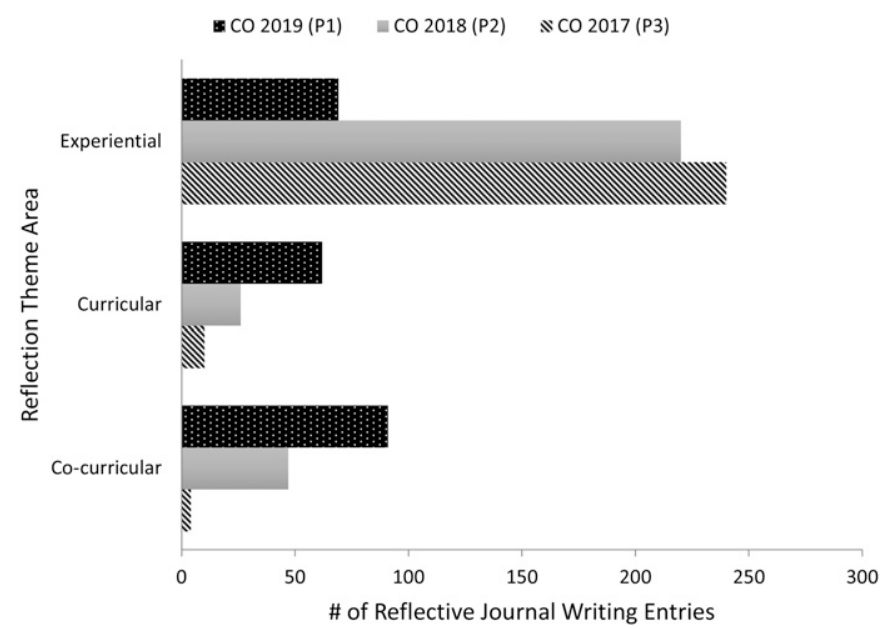

Figure 2. Reflective Journal Writing (RJW) Entries Connected to Programmatic Theme Areas

reflecting on experiences providing community and health care service, $\mathrm{P} 1$ students more frequently reflected on these $15 \%$ of the time, while P2 students reflected on these $6.5 \%$ of the time, and $\mathrm{P} 3$ students, $1.6 \%$ of the time (Figure 4).

In relation to the PIE-RECAP rubric, the areas in which students consistently did well and met expectations included identifying an experience that was most meaningful to them, and identifying what they did not know prior to the experience, as well as using objective language and information to describe an experience. Areas in which help and feedback from graders were constantly necessary included development of SMART goals and using their subjective senses to describe an experience. As students continued to submit entries, they seemed to improve in the area of using their subjective senses and developing more improved SMART goals. Development of SMART goals was an area of continuous struggle for some of the students, and a small percentage (3\%) needed help with these every time they submitted an entry. The number of student entries meeting expectations upon first submission was 648 (84\%), and the number of student entries needing to be rewritten one or more times and resubmitted was 123 (16\%). Of these, $8 \%$ of entries required more than one revision. Additionally, students' selection of the various programmatic, ABOs linked to CAPE 2013 domains resulted in $11 \%$ in domain 1, $29 \%$ in domain $2,40 \%$ in domain 3 , and $20 \%$ in domain 4 (Figure 3).

During the spring semester of the academic year (2016-2017), a reorganization of the program's student advising process prompted a reevaluation of the PIE-RECAP model. A survey was deployed to both students and graders asking about the workload associated with the process, its perceived value and utility, the ability of the 


\section{American Journal of Pharmaceutical Education 2019; 83 (3) Article 6554.}

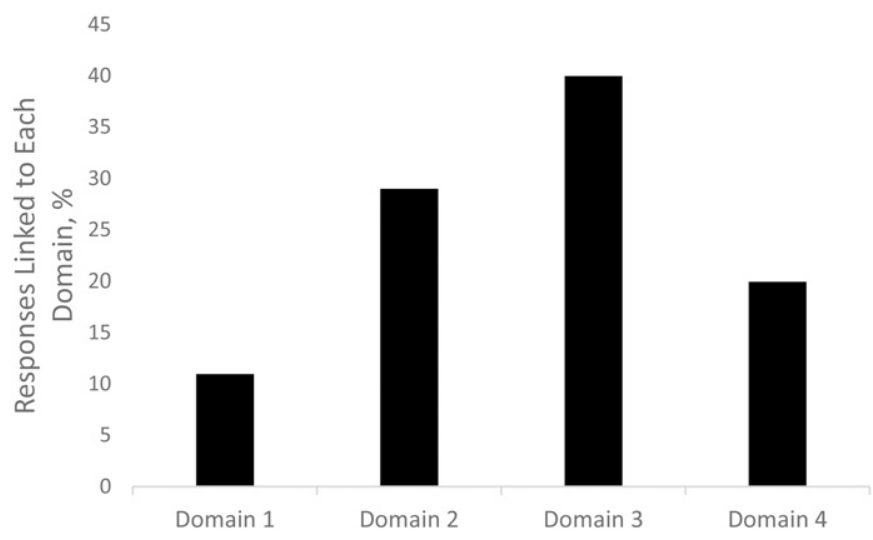

Figure 3. Reflective Journal Writing (RJW) Entries Linked to Programmatic Educational Outcomes by Students

process to help them meet several outcomes tied to PIERECAP, and what the future frequency of the entries should be.

The survey results indicated that both students and graders saw the value of reflection, but students were more likely than faculty members to recommend removing the requirement for the PIE-RECAP reflection from the curriculum. Across both students and graders, there was agreement that the process was useful in a variety of areas, including allowing faculty members to develop a deeper knowledge of their students and providing students practice with which to develop actionable goals. Because of these results, the faculty finally decided that the PIE-RECAP model would be used the next year but that students were only required to complete one PIERECAP model reflection per year: one during their P1 year and another during their $\mathrm{P} 2$ year. The program administration, faculty, and staff (especially those involved in grading student entries) felt the framework had great merit but did not think the frequency of two to three reflections per year was necessary. An additional self-reflection assignment was substituted in the P1 and P2 year where students wrote a letter of introduction to their preceptor in which they identified their strengths and weaknesses. This letter to the preceptor also replaced RJW assignments for students in their APPE year.

Implementation of the PIE-RECAP model resulted in two major proposals for restructuring the curriculum. One faculty grader used feedback from the students' entries to redesign the introductory biochemistry course that occurs at the beginning of the P1 year. Several students had written about the sheer challenge of transitioning to an accelerated curriculum that encompassed a two-week block and culminated with a high-stakes assessment of student competency. In response, the faculty member worked with the school's curriculum committee and various stakeholders to restructure the course to allow students more time for acclimatization (four weeks instead of two weeks). This change allowed for more formative assessments throughout the course prior to the final, cumulative examination.

The other curricular change resulted in a thorough review of student training in the area of community health care outreach to ensure that program faculty members were taking the lead in teaching students best practices early in the program so they could contribute safely and effectively in various patient care activities in the community at different levels, and always while supervised by a qualified and competent preceptor. Based on the findings from this review, physical assessment skills were moved to earlier points in the curriculum to better prepare students for IPPEs.

\section{DISCUSSION}

Pharmacy students across all three classes (P1-P3) at the Pacific University Oregon School of Pharmacy valued the practice skills they learned in the RJW program, both within the classroom and within the experiential curriculum. In their writings, students often commented on how much they valued their pharmacy skills courses, specifically learning point-of-care testing, blood pressure, and immunization training. These skills also were heavily referenced as necessary skills to be able to help the community during a healthcare service outreach. First-year students focused on learning skills during their pharmacy practice skills courses, P2 students commented on using these during cocurricular outreach and volunteering as well as during IPPE rotations, and P3 students commented on using practice skills during their APPEs. Additionally, students commented on the value of the co-curriculum. First-year students identified the ample opportunities in our program to become more involved with the program's leadership, outreach, admissions, mentoring program, and many other programs that we offer to engage our students with the profession. These students commented most frequently on the significance of symbolic cocurricular events in professionalization, such as the White Coat Ceremony, career fair activities, orientation, and even working together more effectively in their assigned teams.

Second-year students commented most frequently on serving their student organizations as leaders and organizers for community outreach events and serving on committees, as well as mentoring P1 students during a semester-long program encouraging direct P1-P2 interactions using clinical case work in the classroom. Third-year students most commonly reflected on their application of practice skills, as well as their abilities to teach others, including patients, other providers, family 


\section{American Journal of Pharmaceutical Education 2019; 83 (3) Article 6554.}

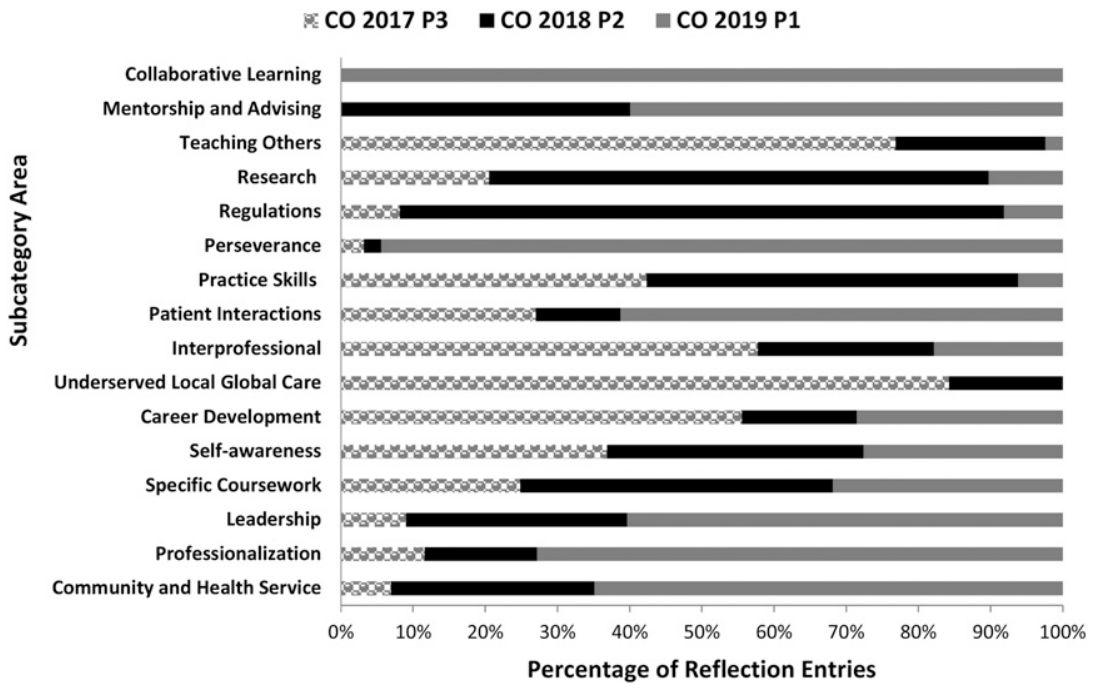

Figure 4. Reflective Journal Writing Entries (\%) Thematically Linked to Subcategory Areas

members, pharmacists, and technicians, among others, during their APPEs.

The content of students' RJW entries illustrated how impactful aspects of our curriculum, co-curriculum, and experiential education opportunities help shape students' global experiences and impressions of the profession. Our program values the development of students' practice skills with the goal of developing "practice ready" graduates, and we see those values reflected in students' entries. Students wrote about their enjoyment of not only learning practice skills but being able to use those skills to help others in their community, including underserved populations. This reflects another value of our program, which is to help the underserved in diverse settings, regions, and care environments. Other examples of the content of students' entries reflecting our program values included entries highlighting how they have faced adversity in our program and have either changed their habits or modified their own behavior to surmount the challenges, such as by preparing for and taking examinations, developing more friendships in the program, seeking help from faculty members and peers, and becoming more involved in the profession in ways that were meaningful and rewarding to them. Additionally, students commented frequently about their interprofessional experiences during the required curriculum, in cocurricular events on community healthcare outreach, and during their clinical experiential rotations.

Although we have decreased the frequency of required RJW assignments using the PIE-RECAP model from two to three times per year to once a year, we have continued to see the value of this framework for reflection in the area of program development and improvement. By reviewing the students' entries and providing them with feedback, we are helping them to develop actionable plans. This mirrors current practices in various industries where yearly employee performance reviews are tied to actionable goals. ${ }^{28-31}$ As professionals, we know the difficulty in developing goals in our own careers, and we also can attest to the challenges and learning that result from formulating even one goal. Anecdotally, faculty members noted that after implementation of the RJW process, students appeared more comfortable with prioritizing patient pharmacotherapy problems and setting therapeutic SMART goals. Yearly analysis of curricular changes, such as moving physical assessment earlier in the curriculum will be shared with the assessment committee and administration so we can identify any themes that might be communicated to the advisory board, alumni board, and preceptor board in order to use students' reflection entries to help with the continuous quality improvement and assessment of our program.

Regarding the PIE-RECAP model itself, faculty members involved in grading may have some ideas on how the framework can be improved. Currently, no ideas to change the process for the incoming year have been implemented or proposed, and we see the model as enduring in many of the domains. For students in need of more guidance on how to start the reflection process, we anticipate providing them with more background information and more examples of how each of the eight sections of the model should be approached. We also plan to expand the amount of time spent discussing what SMART goals are when we introduce the program to incoming students during orientation.

The PIE-RECAP model challenges students in our program to think more holistically about their education, beyond clinical knowledge and the application of 


\section{American Journal of Pharmaceutical Education 2019; 83 (3) Article 6554.}

sciences. The PIE-RECAP model also enabled faculty members to learn more about their students' experiences in pharmacy school and to promote deeper connections that are not only lasting, but also help our faculty members better assist them with advice and direction on career planning and finding their best place in the profession according to their evolving and maturing values.

With regard to resources and infrastructure, we recommend that programs planning to implement the PIE-RECAP model have invested personnel at the administrative, faculty, and staff levels to ensure that the RJW process is sustainable and will be maintained and monitored appropriately. We also advise incorporating more graders into the process who will have an ongoing connection with students, such as a formally assigned advisor/mentor within the program. This makes the process more engaging for both the grader and the student. Additionally, we recommend that programs seek and adopt a process that allows flexibility in how students share RJW entries and portfolio information with "unofficial" mentors to ensure students can gain additional feedback. Based on our experiences with the RAR, we recommend that programs planning to adopt PIE-RECAP and the RAR engage in norming sessions of the rubric to ensure that it fits in with specific expectations they have within their program based on their own unique ABOs and other educational outcomes.

Major limitations of pharmacy school activities like RJW center around the impact of recall bias, as well as the potential problem with proving the general veracity of the entries. Because of the academic schedule and other events and holidays, entries were scheduled three months or more apart. Because of this, a student may have experienced something on day one of that three-month cycle yet not have written about it until weeks later. When we asked them to share their most meaningful learning experience during such intervals, they may have had additional experiences occur after that, making describing the earlier experiences subject to recall bias. They may have also encountered new information that may have changed, how they perceived and reported their experience because they continually learned more about the profession and themselves as they progressed through the program.

In relation to proving the veracity of these entries, they were taken at face value by graders. Students possibly may have created these scenarios. There was no way for us to know if these events happened or not unless they were events that had been well-publicized by the media. As RJW entries tend to be extremely personal and written from the student's unique vantage point, we were hopeful and optimistic that they had not been fabricated. We include this as a limitation so that others in the Academy will be aware that this type of student behavior cannot be ruled out.

The transferability of the PIE-RECAP model and RAR to other pharmacy programs, coupled with our sincere desire to provide open-access to our methods, provides an exciting opportunity to establish meaningful multi-institution collaborations. Such collaborative efforts would have the potential to promote self-awareness in our students and enact positive change in the pharmacy profession.

We anticipate pharmacy educators interested in assessment, accreditation, student leadership development, curricular development, and continuous professional development (among others) will find our work and our findings interesting. Moreover, the PIE-RECAP method is inherently adaptable and can be applied to reflections written for a single class or experience, multiple classes, or an entire course of study towards a degree, and culminate in a capstone project or paper. ${ }^{14,15,21,28,31}$ Because of the diversity of institutions' missions, visions, and values, and how they assess student learning and competencies, there is a great deal of variation in how students and faculty members perceive the value and utility of selfreflection..$^{21,25,26}$ We hope to widely share the ongoing results of implementing PIE-RECAP, including more details about student responses, challenges with the process, grader perspectives on the quality and depth of the work, and the different ways we use data from RJW entries to improve our program and our classroom and experiential curriculum, as well as intersections between PIE-RECAP and our co-curriculum. While PIE-RECAP is based on our specific programmatic $\mathrm{ABO}$, we believe that other programs can take what we have implemented, in part or in its entirety and adopt it into their own practices. Because both PIE-RECAP and the RAR are designed with various effective and evidence-based educational models in mind, and also align with the CAPE 2013 and ACPE 2016, their structures will be useful in various programs within and beyond pharmacy education. As previously mentioned, we have already shared the PIERECAP method through the AACP Assessment Award and are eager to share the RAR and aggregate results reported here to spread interest across the Academy. We foresee the potential for cross-program collaborative scholarship describing the use, results, and pros and cons of the PIE-RECAP model and the RAR to enhance the quality of pharmacy programs and curricula.

\section{CONCLUSION}

The PIE-RECAP model provided a robust mechanism for helping students reflect in a framework grounded in teaching and learning theory and served as an 


\section{American Journal of Pharmaceutical Education 2019; 83 (3) Article 6554.}

applicable tool to help students see an experience or behavior through several diverse lenses at once. The model also helped them create actionable goals for improving outcomes in their personal and professional lives. Future research with PIE-RECAP and the RAR will focus on the intersections between RJW structure and educational psychology. Teaching and learning methods and models, including constructivism, self-directed learning, socialbehavioral learning, cognitive learning, and transformative learning, blend very well with different stages of our model. Linking more of our processes to fundamental, evidence-based ideas within the educational literature will add validity to our RJW structure and further emphasize the need to use evidence from the literature in education as a springboard and foundation for effective teaching in pharmacy education.

\section{ACKNOWLEDGMENTS}

We would like to acknowledge Drs. Leslie Devaud, Eddie Saito, Melanie Foeppel, Ryan Gibbard, Ian Doyle, Brandon Nuziale, Sarah E. White, and Professor Mike Millard for their support as graders in our program's reflective journal writing process.

\section{REFERENCES}

1. Halpern DF. Teaching critical thinking for transfer across domains: dispositions, skills, training, and metacognitive monitoring. Am Psychol. 1998;53(4):449-455.

2. Tate S, Sills M. Development of Critical Reflection in the Health Professions. London, UK: Higher Education Academy, Health Sciences and Practice Subject Centre; 2004.

3. Kember D. Reflective Teaching and Learning in the Health Professions. New York, NY: Wiley-Blackwell Publishing; 2001.

4. Wald HS, Reis SP. Beyond the margins: reflective writing and development of reflective capacity in medical education. $J$ Gen Intern Med. 2010;25(7):746-749.

5. Mamede S, Schmidt HG, Penaforte JC. Effects of reflective practice on the accuracy of medical diagnoses. Med Educ. 2008;42(5):468-475.

6. Sen BA. Reflective writing: a management skill. Library Manage. 2010;31(1/2):79-93.

7. Wetmore AOK, Boyd LD, Bowen DM, Pattillo RE. Reflective blogs in clinical education to promote critical thinking in dental hygiene students. $J$ Dent Educ. 2010;74(12):1337-1350.

8. Embo MP, Driessen E, Valcke M, Van Der Vleuten CP. Scaffolding reflective learning in clinical practice: a comparison of two types of reflective activities. Med Teach. 2014;36(7):602-607. 9. McKay FH, Dunn M. Student reflections in a first year public health and health promotion unit. Reflect Pract. 2015;16(2):242-253. 10. Mezirow J. Transformative Dimensions of Adult Learning. San Francisco, CA: Jossey-Bass; 1991.

11. Tsingos-Lucas C, Bosnic-Anticevich S, Schneider CR, Smith L. The effect of reflective activities on reflective thinking ability in an undergraduate pharmacy curriculum. Am J Pharm Educ.

2016;80(4):Article 65.
12. Mann K, Gordon J, MacLeod A. Reflection and reflective practice in health professions education: a systematic review. $A d v$ Health Sci Educ Theory Pract. 2009;14(4):595-621.

13. Tsingos C, Bosnic-Anticevich S, Smith L. Learning styles and approaches: can reflective strategies encourage deep learning? Curr Pharm Teach Learn. 2015;7(4):492-504.

14. Hobson EH, Johnston PE, Spinelli AJ. Staging a reflective capstone course to transition PharmD graduates to professional life. Am J Pharm Educ. 2015;79(1):Article 14.

15. Plaza CM, Draugalis JR, Slack MK, Skrepnek GH, Sauer KA. Use of reflective portfolios in health sciences education. Am J Pharm Educ. 2007;71(2):Article 34.

16. Schon D. The Reflective Practitioner: How Professionals Think in Action. New York, NY: Basic Books; 1984.

17. Maellaro R. The learning journal bridge: from classroom concepts to leadership practices. J Leadersh Educ. 2013;12(1):234-244.

18. Olsen PE. The use of portfolios in leadership education.

J Leadersh Educ. 2009;7(3):20-27.

19. Kolb DA. Experiential Learning: Experience as the Source of Learning and Development. Englewood Cliffs, NJ: Prentice Hall; 1983.

20. Roberts C. Developing future leaders: the role of reflection in the classroom. J Leadersh Educ. 2008;7(1):116-130.

21. Boyd B, Williams J. Developing life-long learners through personal growth projects. J Leadersh Educ. 2010;9(2):144-150. 22. Accreditation Council for Pharmacy Education. Accreditation standards and key elements for the professional program in pharmacy leading to the doctor of pharmacy degree. Standards 2016. https:// www.acpe-accredit.org/pdf/Standards2016FINAL.pdf. Accessed June 1, 2017.

23. Bloom B, Engelhart M, Furst E, Hill W, Krathwohl D. Taxonomy of Educational Objectives: The Classification of Educational Goals. Handbook I: Cognitive Domain. New York, NY: David McKay Company; 1956.

24. Krathwohl D, Bloom B, Masia B. A Taxonomy of the Psychomotor Domain: A Guide for Developing Behavioral Objectives. New York, NY: David McKay Company; 1964. 25. Tsingos C, Bosnic-Anticevich S, Smith L. Reflective practice and its implications for pharmacy education. Am J Pharm Educ. 2014;78(1):Article 18.

26. Tsingos C, Bosnic-Anticevich S, Lonie JM, Smith L. A model for assessing reflective practices in pharmacy education. Am J Pharm Educ. 2015;79(8):Article 124.

27. Hammer D. What matters in developing professionals and professionalism? In: Sylvia LM, Barr JT, eds. Pharmacy Education: What Matters in Learning and Teaching. Sudbury, MA: Jones \& Bartlett Learning; 2011:239.

28. Duffy FD, Holmboe ES. Self-assessment in lifelong learning and improving performance in practice: physician know thyself. JAMA. 2006;296:1137-1139.

29. Interprofessional Education Collaborative. Core competencies for interprofessional collaborative practice. https://www.aacom.org/ docs/default-source/insideome/ccrpt05-10-11.pdf?

sfvrsn $=77937 \mathrm{f972}$. Accessed June 1, 2017.

30. Grice GR, Monson K, Pitlick J, et al. Developing a

professionalism plan. Innov Pharm. 2013;4(1):Article 103

31. Coulehan J, Granek IA. Commentary: "I hope I'll continue to grow": rubrics and reflective writing in medical education. Acad Med. 2012;87(1):8-10. 


\section{American Journal of Pharmaceutical Education 2019; 83 (3) Article 6554.}

\section{Appendix 1. Reflective Journal Writing Assessment Rubric (RAR)}

This rubric will help the grader determine whether the student met expectations regarding the PIE-RECAP Reflective Journal Writing assignments. One instance of "Does Not Meet Expectations" (DNME) is sufficient grounds to have the student re-write the reflection entry and re-submit it. You must complete ALL components of each entry.

To the grader: Please provide specific comments to help guide the student in their re-write if you determine that the student does not meet expectations (DNME); please provide comments for any section noted DNME.

To the student: Please review the "Additional Comments" provided by the grader to help you re-submit a re-write that meets expectations. Please use complete sentences and professional writing. Please pay special attention to clarity - that is a component of every sub-section below. Examples will be provided. 
American Journal of Pharmaceutical Education 2019; 83 (3) Article 6554.

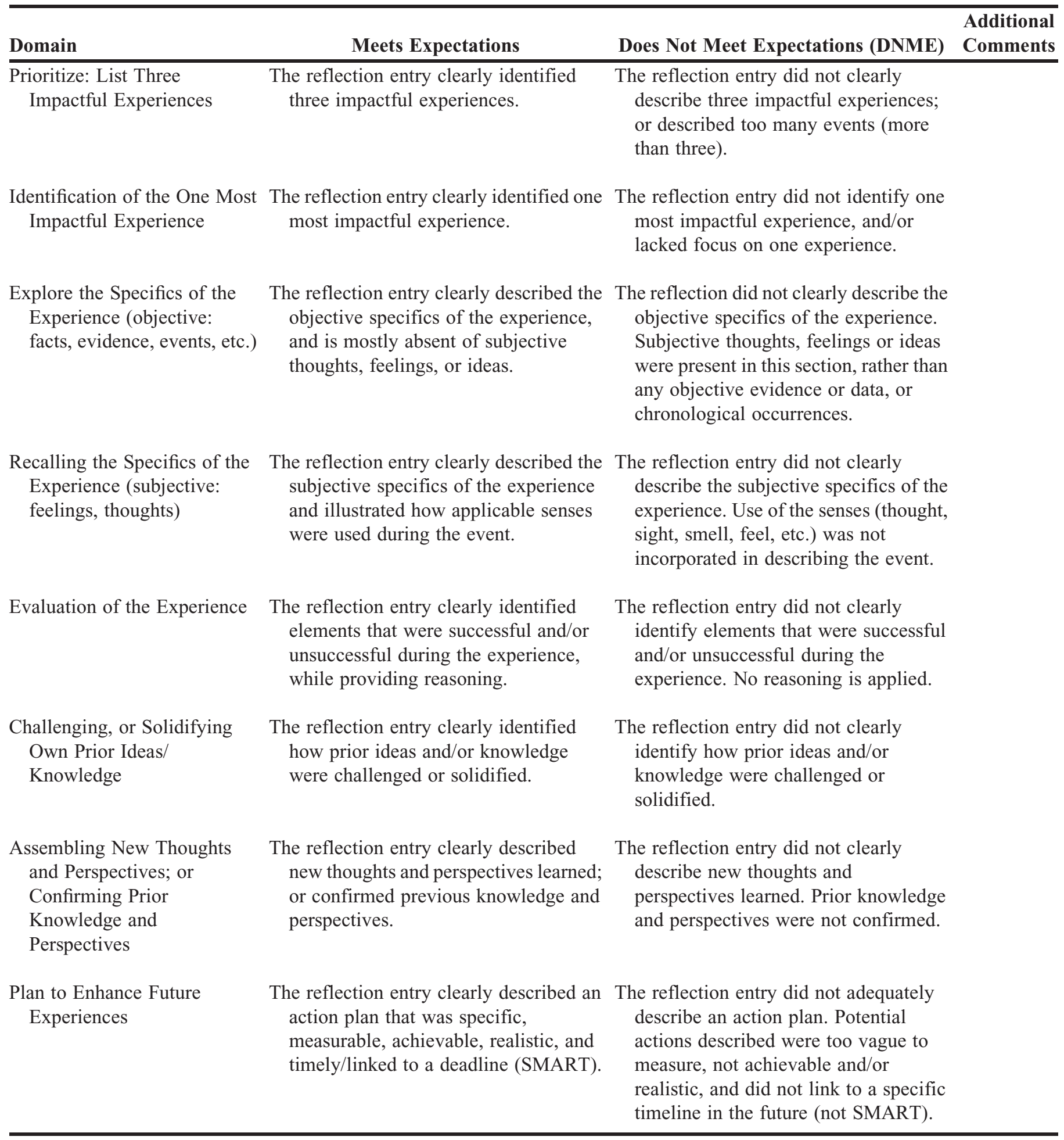

